\title{
A complex rupture image of the 2011 off the Pacific coast of Tohoku Earthquake revealed by the MeSO-net
}

\author{
Ryou Honda $^{1}$, Yohei Yukutake ${ }^{1}$, Hiroshi Ito ${ }^{1}$, Masatake Harada ${ }^{1}$, Tamotsu Aketagawa $^{1}$, Akio Yoshida $^{1}$, \\ Shin'ichi Sakai ${ }^{2}$, Shigeki Nakagawa ${ }^{2}$, Naoshi Hirata ${ }^{2}$, Kazushige Obara ${ }^{2}$, and Hisanori Kimura ${ }^{3}$ \\ ${ }^{1}$ Hot Springs Research Institute of Kanagawa Prefecture, 586 Iriuda, Odawara, Kanagawa 250-0031, Japan \\ ${ }^{2}$ Earthquake Research Institute, University of Tokyo, 1-1-1 Yayoi, Bunkyo-ku, Tokyo 113-0032, Japan \\ ${ }^{3}$ National Research Institute for Earth Science and Disaster Prevention, 3-1 Tennodai, Tsukuba, Ibaraki 305-006, Japan
}

(Received April 10, 2011; Revised May 18, 2011; Accepted May 29, 2011; Online published September 27, 2011)

\begin{abstract}
Strong ground motions from the 2011 off the Pacific coast of Tohoku Earthquake, the most powerful earthquake to have occurred in and around Japan after the installation of a modern seismic network, were recorded for more than 300 seconds by a dense and wide-span seismic network, the Metropolitan Seismic Observation Network (MeSO-net), installed around the Tokyo metropolitan area about $200 \mathrm{~km}$ away from the epicenter. We investigate the rupture process of the earthquake in space and time by performing semblance-enhanced stacking analysis of the waveforms in a frequency range of 0.05 to $0.5 \mathrm{~Hz}$. By projecting the power of the stacked waveforms to an assumed fault plane, the rupture propagation image of the large and complex earthquake has been successfully obtained. The seismic energy was mainly generated from the off-shore areas of about $100 \mathrm{~km}$ away from the coast in Miyagi and Fukushima Prefectures. The shallow and eastern part of the fault along the Japan trench off Miyagi Prefecture released strong seismic energy which might have been related to the excitation of gigantic tsunami. In contrast, the southern shallow part of the fault plane, off Ibaraki Prefecture, released only minor seismic energy. Our analysis suggests that the focal areas combining both the officially-forecasted Miyagioki earthquake and those of historical earthquakes that occurred off the coast of Fukushima Prefecture in 1938 were broken, resulting in the 2011 great $M 9$ earthquake.
\end{abstract}

Key words: The 2011 Tohoku Earthquake, rupture images, back projection, semblance, MeSO-net.

\section{Introduction}

The 2011 Tohoku Earthquake, which caused a large number of deaths and missing people and brought about serious damage to nuclear power plants, occurred on 11th March, 2011, at 14:46 (JST). While the magnitude was first announced as $7.9\left(M_{\mathrm{JMA}}\right)$ by the Japan Meteorological Agency (JMA), it was corrected to $9.0\left(M_{\mathrm{w}}\right)$ after two days. Aftershocks in the first three days occurred east off the Pacific coast in a wide region of about $400 \mathrm{~km}$ length and $200 \mathrm{~km}$ width. Strong ground motion data obtained by the NIED K-NET stations along the coastline indicated that multiple asperities ruptured during the main shock (Noguchi and Furumura, 2011).

Coastal areas have repeatedly suffered severe damage by large earthquakes in the subduction zone. For example, $M 7.5, M 7.8$ and $M 7.4$ earthquakes hit the coast of Miyagi Prefecture in 1936, 1978 and 2005. The Headquarters for Earthquake Research Promotion published a longterm earthquake hazard map where the concept of a characteristic earthquake played a substantial role. The occurrence probability of the next one during the coming 30 years has been evaluated at as high as $90 \%$ and the asperity of the 1978 event estimated by Yamanaka and Kikuchi (2003)

Copyright (c) The Society of Geomagnetism and Earth, Planetary and Space Sciences (SGEPSS); The Seismological Society of Japan; The Volcanological Society of Japan; The Geodetic Society of Japan; The Japanese Society for Planetary Sciences; TERRAPUB.

doi:10.5047/eps.2011.05.034 was considered to be typical (the Headquarters for Earthquake Research Promotion, 2011). In the region of offFukushima, to the south of off-Miyagi, a series of $M 7+$ earthquakes occurred in May and November, 1938. This series of earthquakes is known as the 1938 Shioya-oki cluster event. No record of large earthquakes exists in the offFukushima region for at least 400 years before the 1938 event. Abe (1977) suggested that a large part of accumulated strains in the region is being released by aseismic slips. In the long-term hazard map, the occurrence probability of a large earthquake $(M>7)$ in this region was evaluated to be very low. On the other hand, $M 7$ class earthquakes have occurred repeatedly in the off-Ibaraki region at an interval of 20-30 years. The last one occurred in May 2008 so that it was considered that a large earthquake would not occur in this region in the near future. Recently, Kanamori et al. (2006) pointed out that the seismic slip rate estimated from historical earthquakes accounts only for $25 \%$ of the plate convergence rate in the off-Miyagi region. They also pointed out that the seismic slip rate in the $200 \mathrm{~km}$ segment to the south of the region is similarly very low. They suggested two possibilities to explain the apparent missing of the plate coupling: (1) a larger part of the relative plate motion is consumed by aseismic slips; (2) the accumulated strain will be eventually released by huge earthquakes which might cause severe damage to the Tohoku region. 


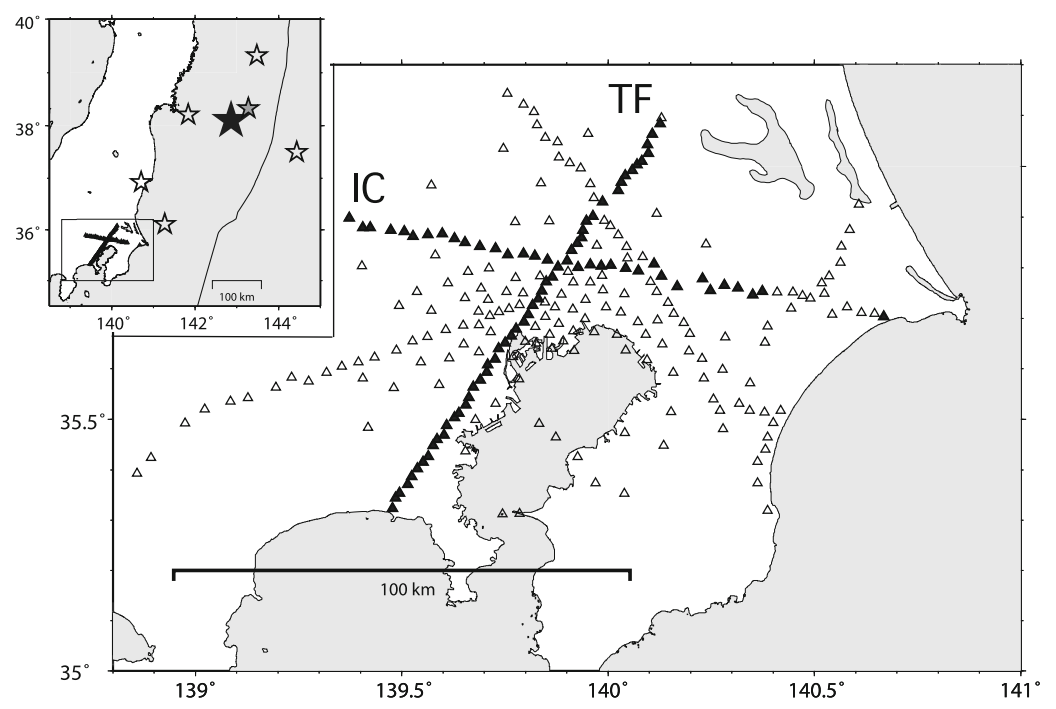

Fig. 1. Location map of the seismogram stations of the Metropolitan Seismic Observation Network (MeSO-net). Seismographs at stations of Tsukuba-Fujisawa array (TF) and Iruma-Chosi array (IC), which are plotted by solid triangles, are used in this study. The inset on the left top shows epicenters of the main shock (black star), large aftershocks over $M 7$ (blank stars) and the preshock (gray star) determined by the JMA. The solid line represents the Japan trench.

The purpose of this study is to elucidate the asperity distribution of the 2011 giant earthquake. We expect that clarification of the asperities will provide valuable information to understand the scheme of plate coupling in this region as well as relations between past large earthquakes, the great 2011 event and possible future ruptures. A recently proposed promising method to investigate the earthquake rupture process utilizes array data from a dense seismic network. Ishii et al. (2005) successfully imaged rupture propagation of the 2004 Sumatra-Andaman earthquake by stacking seismic waveforms on the fault plane. Honda et al. (2008) studied the location of a minor asperity of the 2003 Tokachi-oki earthquake by applying semblance analysis. Further, applying the back-projection method to the 2007 Niigataken Chuetsu-oki earthquake, Honda and Aoi (2009) obtained the distribution of asperities and the rupture propagation velocity. These studies showed that the backprojection method is very useful in analyzing large and/or complex fault processes. We analyze the fault motion of the 2011 gigantic earthquake by applying the back-projection method to seismic data from a dense array.

\section{Fault Model}

In this study, we adopt the hypocenter determined by the JMA $\left(142.861^{\circ} \mathrm{E}, 38.103^{\circ} \mathrm{N}, 23.7 \mathrm{~km}\right)$, and assume that the strike and dip angle of the fault plane are $\mathrm{N} 200^{\circ} \mathrm{E}$ and $12^{\circ}$, respectively. The fault plane with a length of $600 \mathrm{~km}$ and a width of $270 \mathrm{~km}$ that covers the aftershock area is divided into subfaults with a dimension of $30 \mathrm{~km} \times 30 \mathrm{~km}$. In order to diminish the calculation time and memory size, we presuppose that the rupture velocity is smaller than $4 \mathrm{~km} / \mathrm{s}$ and that each subfault ruptures within $80 \mathrm{~s}$. In principle, these constraints are not necessary. We confirmed in a preliminary analysis that the result did not change significantly if the rupture velocity is taken to be $4.5 \mathrm{~km} / \mathrm{s}$ and the duration time $140 \mathrm{~s}$ respectively, except that the noise level of the stacked waveforms rises somewhat.

\section{Data and Method}

A dense and wide-span seismograph network, called the MeSO-net (Hirata et al., 2009; Sakai and Hirata, 2009), has been developed under the "Special Project for Earthquake Disaster Mitigation in the Tokyo Metropolitan Area" since 2007 (Fig. 1). Data of strong ground-motions at 249 stations installed in and around the Tokyo Metropolitan Area are automatically transmitted in real time to the operation center situated in the Earthquake Research Institute (ERI). Separations between stations are mostly several kilometers only, while the network extends over $100 \mathrm{~km}$. We used strong ground-motions observed at Tsukuba-Fujisawa and Iruma-Choshi linear arrays that are approximately oriented parallel and perpendicular to the fault strike, respectively. The total number of sites used in the analysis is 84 . Generally, seismic wave-lengths usable in array analysis are constrained by the spacing of stations. Seismic wave-lengths should be more than twice the spacing of stations. In view of the site separation, waveforms were band-pass filtered in the frequency range of $0.05-0.5 \mathrm{~Hz}$.

Figure 2 displays the band-passed acceleration waveforms placed in the order of latitude of the stations. The abscissa represents elapsed time from the origin time in seconds. Series of coherent wave trains can be recognized in the waveforms. Wave trains with the largest amplitude are seen 180 to $200 \mathrm{~s}$ after the origin time. Some other wave trains corresponding to different apparent velocities are also observed before and after the arrival of the largest wave. The composition of the waves with different apparent velocities and amplitudes suggest a complex rupture process of the main shock.

The back-projection method is based on slant stack processing (e.g., Yilmaz, 1987). Band-pass filtered waveforms are stacked taking the travel-time difference into account after rotating the horizontal components into radial and transverse directions with respect to the line connecting stations and subfaults. The travel time for every pair of subfaults 

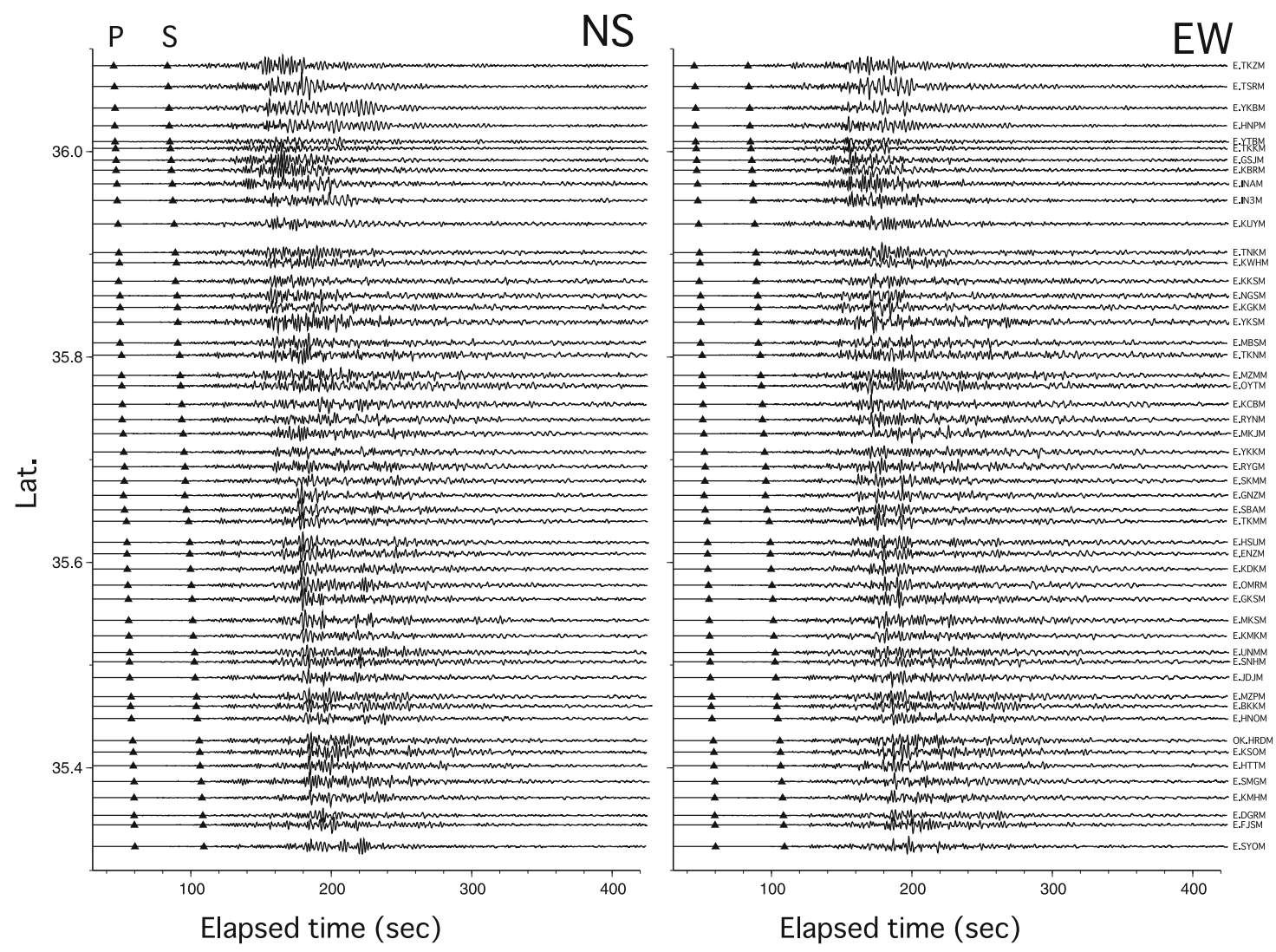

Fig. 2. Acceleration waveforms observed at stations of the Tsukuba-Fujisawa array. The waves are band-pass filtered between $0.05-0.5 \mathrm{~Hz}$. The left and right panels show the NS and EW component, respectively. The abscissa represents the elapsed time from the origin time. The station names are indicated on the right of the traces. Manually picked $P$-wave arrivals and $S$-wave arrivals that are estimated from theoretical $S$ - $P$ time are indicated by black triangles.

and stations was calculated using ray theory. The stacked waveform for a particular subfault is regarded as a time series of energy release at that subfault. The variation of arrival times of waves observed in the central part of the Tokyo area, where a thick sediment layer exists underneath, is large compared to that at other stations. The local velocity structure directly beneath the observation array, such as a sediment layer, could produce significant variations in the travel time which might affect the results of the stacking procedure. In order to avoid an error caused by the local velocity structure when making the back-projection image, we applied a site correction to the arrival times. The site correction for each of the stations was estimated from observed-calculated arrival time residuals in the determination of the hypocenters of earthquakes occurring around the Kanto area.

Although the high density and wide span of the observation network substantially reduce noises which come from areas other than asperities, we have introduced additional data-processing steps to improve the resolution. We have applied $N$ th root stacking (e.g., Rost and Thomas, 2002) and semblance-enhanced stacking (Matsumoto et al., 1999) to the waveforms to intensify coherent wave energy. First, waveforms are stacked using $N$ th root stacking at a certain time corresponding to the center of the semblance time window. Then, the stacked amplitude is multiplied by the semblance value calculated for the time window. We selected the 4 th root in the stacking procedure and $8 \mathrm{~s}$ as the sem- blance time window. By repeating this procedure for all subfaults and times, we obtain the released seismic energy from each subfault as a function of time. Finally, integrating the absolute values of the time series of the released energy with respect to time, we obtain the average of the integrated values for the horizontal two components that are supposed to represent the total energy released from the subfault. Thus, the amplitudes in the back-projection image are considered to be proportional to the radiated seismic energy. What physical meaning should be assigned to the stacked value is still a challenging problem. Here we are interested in estimating the extent, velocity, duration of the rupture and direction of the propagation in performing the back-projection analysis.

\section{Results}

Figure 3 shows the distribution of the normalized total energy release on the assumed fault plane. The results for the preshock and the largest aftershock are shown as well. The area where significant energy was released extends eastward to the zone close to the Japan trench. Considerable seismic energy was also radiated from the area off Fukushima Prefecture. The rupture was terminated at the area off the coast of Ibaraki Prefecture where the largest aftershock occurred. The north and south edges of the rupture area are adjacent to the asperities of the 1968 Tokachi-oki earthquake (Nagai et al., 2001) and the 2008 Ibaraki-oki earthquake (Nagoya university, 2008). Large aftershocks 


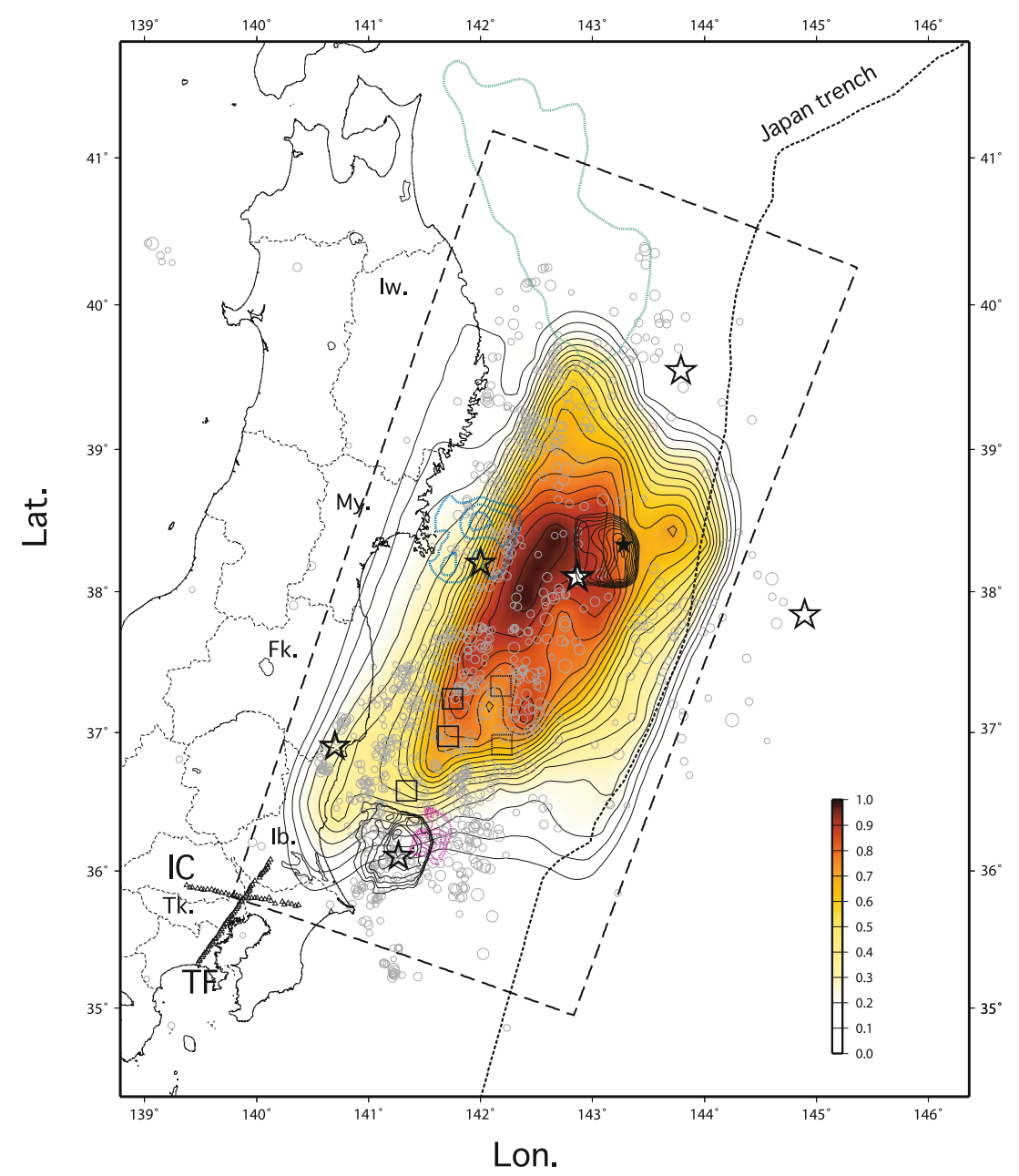

Fig. 3. The distribution of normalized total energy release on the assumed fault plane. The dotted rectangle denotes the assumed fault plane. Gray circles show epicenters of aftershocks $(M>4)$ in the first three weeks after the occurrence of the main shock whose epicenter is plotted by a white star. The black star indicates the $M 7.4$ preshock that occurred two days before the main shock. Epicenters of large aftershocks $(M>7)$ are denoted by blank stars. Distributions of the released energy estimated by the back-projection method for the preshock and the largest aftershock are indicated by thick solid contours. Dotted light blue, green and magenta contours mark estimated asperities for the 1978 Miyagi-oki earthquake, 1968 Tokachi-oki earthquake and 2008 Ibaraki-oki earthquake, respectively. Squares represent epicenters of the 1938 Shioya-oki cluster event for which thrust type and normal type shocks are plotted by solid squares and dotted squares, respectively. Iw., My., Fk., Ib., and Tk. indicate Iwate, Miyagi, Fukushima, Ibaraki Prefectures and Tokyo, respectively.

$(M>7)$ occurred around the area where substantial energy was radiated.

Snapshots representing the propagation of the rupture in 10-s time windows are shown in Fig. 4. The northern part of the fault plane ruptured during the first $80 \mathrm{~s}$. Strong seismic energy was released near the Japan trench during the early stage of this giant event. This zone corresponds to the source area of the gigantic tsunami which resulted in severe damage to the coast of northeastern Japan (Maeda et al., 2011). A fair amount of seismic energy was also released from the landward area corresponding to the source region of the expected Miyagi-oki earthquake, although the released energy was not very large $(30-40 \%$ of the maximum value).

Our results suggest that the rupture near the epicenter shortly after the nucleation of the giant earthquake was complex. The rupture propagated eastwards in the first $40 \mathrm{~s}$, and extended northwards in the next $20 \mathrm{~s}$, and then headed back to the epicenter. On the other hand, the propagation of the rupture during the later stage was relatively smooth.
Southern parts of the fault plane ruptured 70-150 s after the initiation, and the rupture terminated in the area off the coast of Ibaraki Prefecture. The total duration time of the rupture is estimated to be about $150 \mathrm{~s}$.

In Fig. 5, rupture times of subfaults, where more than $10 \%$ of the maximum energy was released, are plotted against their epicentral distances. The rupture time here means the time at which the stacked waveform on a specific subfault takes its maximum value. The average rupture velocity inferred from Fig. 5 is about $2.0 \mathrm{~km} / \mathrm{s}$, which is considerably smaller than the $S$-wave velocity in the source region. However, the rupture propagated with a greater velocity of about $3.5-4.0 \mathrm{~km} / \mathrm{s}$ in the region to the south of the epicenter.

\section{Discussion and Conclusions}

We have successfully described the rupture process of the 2011 off the Pacific coast of Tohoku Earthquake applying a back-projection approach. A map of the total energy released from each subfault (Fig. 3) shows the extent of the 

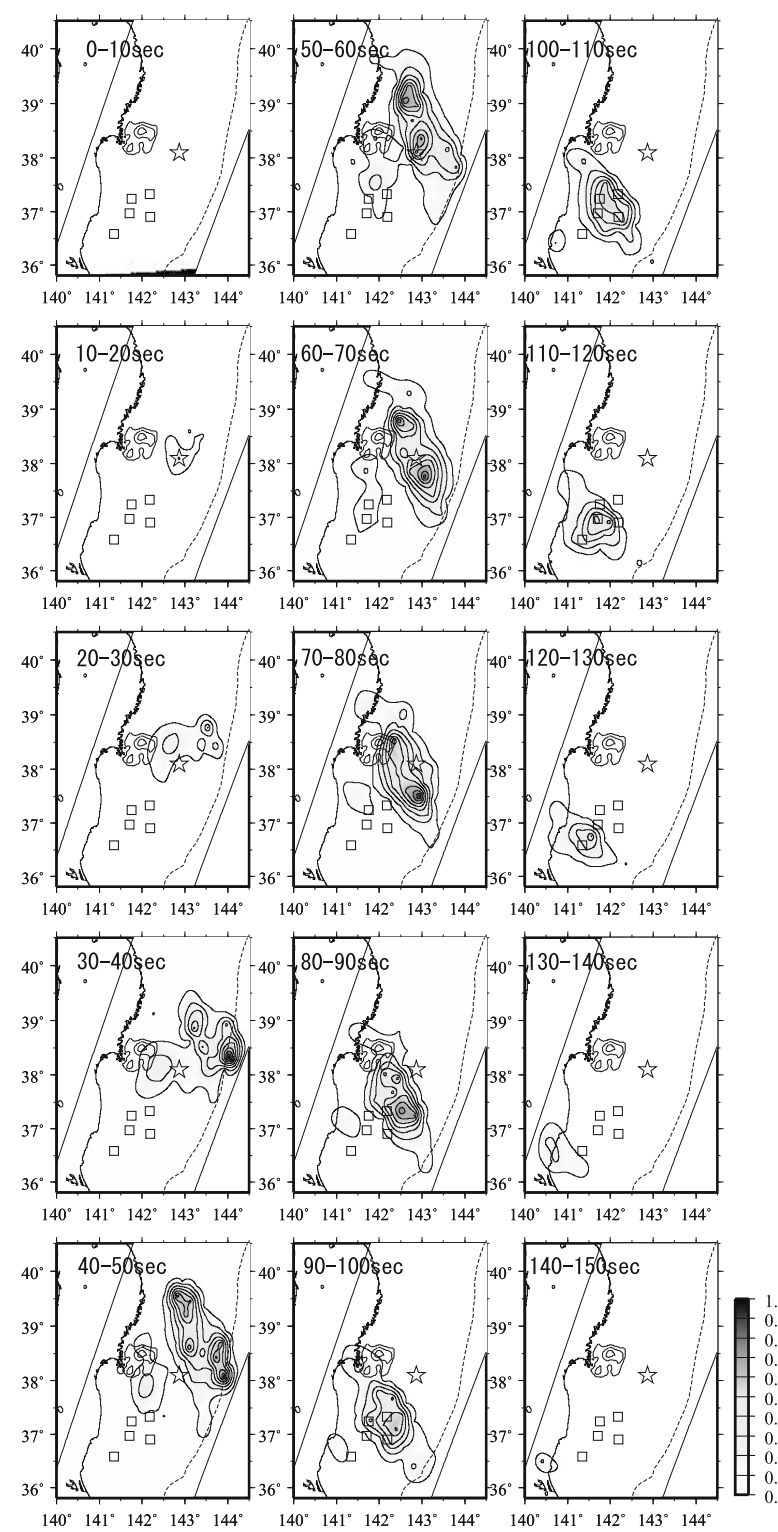

Fig. 4. Snapshots of seismic energy release in 10-s time windows. Note that a fair amount of seismic energy was released from the estimated asperity area of the anticipated Miyagi-oki earthquake at times about 40-60 s after the rupture initiation. Source regions of the 1938 Shioya-oki cluster event also ruptured 100-130 s after the initiation.

rupture clearly. The fault plane taken in the analysis is wide enough to include the focal region of the largest aftershock. Note that the energy release from the epicenter of the largest aftershock is small. This indicates that the rupture terminated before reaching the source region of the largest aftershock. Because the MeSO-net has enough resolution in the hypocenter determination of earthquakes occurring in the area east-off Ibaraki Prefecture, we believe that the southern border of the rupture of the main shock is well delineated. On the other hand, the northern border of the rupture is somewhat uncertain. Our result indicates that large energy was released offshore of Iwate Prefecture (more than $39.5 \mathrm{~N}$ ). However, the displacement estimated from the analysis of ocean bottom pressure sensors in that area was not so large (Maeda et al., 2011).

The focal area of the expected Miyagi-oki earthquake

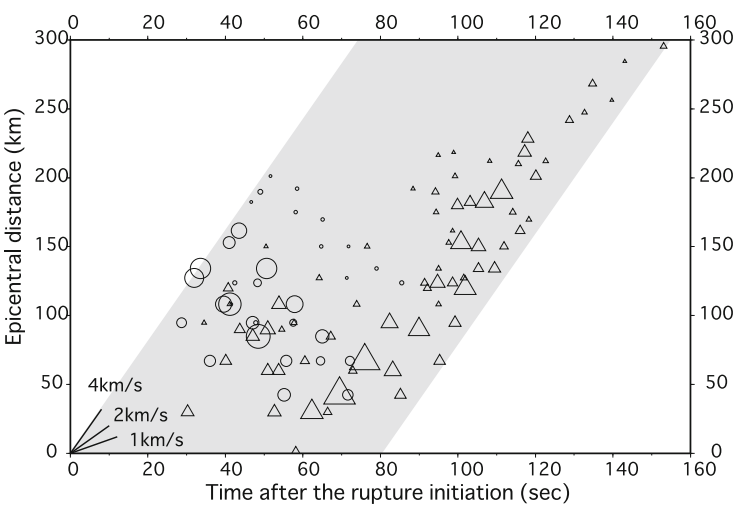

Fig. 5. Scatter plot of rupture time of each subfault against its epicentral distance. The rupture time means the time at which the stacked waveform for a subfault showed its maximum value. The shadowed zone indicates constraint on the time window within which subfaults are allowed to rupture in the analysis. Circles are for subfaults on the northern side of the epicenter and triangles are for subfaults on the southern side. Size of plotted symbols represents the magnitude of the maximum amplitude.

was broken 40-60 s after the initiation of the rupture, although the contribution of the radiated energy to the total energy release was not so large. The source region of the 1938 Shioya-oki cluster event where it has been considered that most of the accumulated strains are released by aseismic slips (Abe, 1977) also ruptured during this $M 9$ event about $90-130 \mathrm{~s}$ after its initiation. The source region of the preshock seems to have released seismic energy as well, although the spatial resolution inferred from the grid spacing of $30 \mathrm{~km}$ may be not sufficient to conclude this convincingly. It should also be added that the source region of the largest aftershock, off-Ibaraki Prefecture, overlaps partly with the focal region of the earthquake which occurred in May 2008. These observations indicate that large or significant seismic energy was released from the regions where accumulated strains are supposed to have been already released by recently-occurred earthquakes or by aseismic slips.

From the point of view of rupture propagation, the complexities in rupture velocity and the directivity are remarkable. The rupture around the hypocenter in the early stage was especially complicated, while the southward propagation of the rupture in the later stage was relatively fast and smooth. The average propagation velocity of the rupture estimated from the rupture time (i.e., the time that energy was mostly released) at each subfault is considerably small.

We feel these observations contribute to understanding the mechanism of earthquake occurrence in the subduction zone. One other aspect worth mentioning is that we do not know, at the present time, whether most of the accumulated strain energy in these source regions has been released by the gigantic event or whether a substantial amount still remains.

Acknowledgments. We would like to thank Dr. Takuto Maeda for his valuable comments about tsunami source regions around Japan. We are very grateful to Professor Yomogida for his valuable advices, especially about the Shioya-oki event. We thank Dr. M. Mai and an anonymous reviewer for carefully reviewing our 
manuscript and making many helpful comments. The present work is partly supported by the Special Project for Earthquake Disaster Mitigation in Tokyo Metropolitan Area of the Japanese Ministry of Education, Culture, Sports, Science and Technology (MEXT).

\section{References}

Abe, K., Tectonic implications of the large Shioya-oki earthquakes of 1938, Tectonophysics, 41, 269-289, 1977.

Hirata, N., S. Sakai, H. Sato, K. Satake, and K. Koketsu, An outline of the Special Project for Earthquake Disaster Mitigation in the Tokyo Metropolitan Area-Subproject I: Characterization of the plate structure and source faults in and around the Tokyo Metropolitan area, Bull. Earthq. Res. Inst. Univ. Tokyo, 84, 41-56, 2009 (in Japanese).

Honda, R. and S. Aoi, Array back-projection imaging of the $2007 \mathrm{Ni}$ igataken Chuetsu-oki Earthquake striking the world's largest nuclear power plant, Bull. Seismol. Soc. Am., 99, 141-147, 2009.

Honda, R., S. Aoi, H. Sekiguchi, and H. Fujiwara, Imaging an asperity of the 2003 Tokachi-oki earthquake using a dense strong-motion seismograph network, Geophys. J. Int., 172, 1104-1116, 2008.

Ishii, M., P. M. Shearer, H. Houston, and J. E. Vidale, Extent, duration and speed of the 2004 Sumatra-Andaman earthquake imaged by the Hi-net array, Nature, 435, 933-936, doi10.1038/nature03675, 2005.

Kanamori, H., M. Miyazawa, and J. Mori, Investigation of the earthquake sequence off Miyagi prefecture with historical seismograms, Earth Planets Space, 58, 1533-1541, 2006.

Maeda, T., T. Furumura, S. Sakai, and M. Shinohara, Significant tsunami observed at ocean-bottom pressure gauges during the 2011 off the $\mathrm{Pa}$ cific coast of Tohoku Earthquake, Earth Planets Space, 63, this issue, 803-808, 2011.

Matsumoto, S., K. Obara, K. Yoshimoto, T. Saito, A. Hasegawa, and A.
Ito, Imaging of inhomogeneous structure of the crust beneath Ou backbone range, northeastern Japan, based on small aperture seismic array observations, Zisin, 52, 283-297, 1999 (in Japanese with English abstract).

Nagai, R., M. Kikuchi, and Y. Yamanaka, Comparative study on the source process of recurrent large earthquakes in Sanriku-oki region: the 1968 Tokachi-oki earthquake and the 1994 Sanriku-oki earthquake, Zisin, 554, 267-280, 2001 (in Japanese with English abstract).

Nagoya university, Source process of Off-Ibaraki earthquake on May 8, 2008 (Mj6.4, 7.0), Rep. Coord. Comm. Eearthq. Predict., 80, 108-110, 2008 (in Japanese).

Noguchi, S. and T. Furumura, The rupture process of the earthquake, found directly on the distribution of the seismic ground motion, http:// outreach.eri.u-tokyo.ac.jp/eqvolc/201103_tohoku/\#gmsource, 2011.

Rost, S. and C. Thomas, Array seismology: methods and applications, Rev. Geophys., 40, 1008, doi:10.1029/2000RG000100, 2002.

Sakai, S. and N. Hirata, Distribution of the Metropolitan Seismic Observation network, Bull. Earthq. Res. Inst. Univ. Tokyo, 84, 57-70, 2009 (in Japanese).

The Headquarters for Earthquake Research Promotion, http://www.jishin. go.jp/main/chousa/09mar_sanriku/sanriku_boso_2_hyoka.pdf, 2011.

Yamanaka, Y. and M. Kikuchi, Asperity map along the subduction zone in northeastern Japan inferred from regional seismic data, J. Geophys. Res., 109, B07307, doi:10,1029/2003JB002683, 2003.

Yilmaz, Ö., Seismic Data Processing, edited by Stephen M. Doherty, 526 pp, The Society of Exploration Geophysics, Tulsa, Oklahoma, 1987.

R. Honda (e-mail: ryou@onken.odawara.kanagawa.jp), Y. Yukutake, H. Ito, M. Harada, T. Aketagawa, A. Yoshida, S. Sakai, S. Nakagawa, N. Hirata, K. Obara, and H. Kimura 